\title{
Application Study of Smart Campus Based on Mobile Internet
}

\author{
Zhang Xiao-bao, Wu Yu-lan \\ Nanchang University College of Science and Technology
}

\begin{abstract}
With the popularization of smart terminals and expanding coverage of third/fourth generation wireless LAN, students and staffs prefer to use mobile terminals to access to internet anywhere and anytime so that spare time can be fully taken advantage of. This paper describes a smart campus platform based on mobile Internet, aiming to establish a new intelligent platform adopted in intelligent environment to serve teaching, research, administration and campus life. Besides, it adopts information integrating and processing technology to establish personalized news service platform with campus as the topic which can reduce information overloading by exploring users' interests so as to help users access to the internet anywhere and anytime.
\end{abstract}

KeyWords-Information Processing; Computer Application; Smart Campus; Mobile Internet

\section{INTRODUCTION}

At present, university information construction has been accelerated and most universities have established and adopted digital campus platforms (including website, and OA system and teaching management systems), which do not only provide office and basic teaching management service but also make it convenient for teachers as well as students to carry out work. However, problems come, for example lack of comprehensive arrangement and guidance in the early construction stage, the systems are messy, the information island phenomenon among portal website, information management service and office automation system is obvious; it is difficult to conveniently acquire various information and service via a single Web interface; information resource utilization is low and messy information cannot provide users with personalized service and help managers in terms of making decisions.

Therefore, it is necessary and meaningful to establish a smart campus service platform based on mobile internet.
This paper takes mobile internet as the background, and work, life service requirement of students and teachers as starting points to mainly elaborate a smart campus service platform based on mobile internet which include diverse functions such as personalized news, active push and data analysis and can enrich and innovate the campus management model.

\section{INFORMATION ACTIVE PUSH TECHNOLOGY}

General information service platform publishes information on Web sites, waiting for users to acquire. Users have to retrieve the information with the assistance of search engine and handiwork search. As a result, the information cannot be timely delivered to them which shall lose its potential value.

When the internet information is explosively growing, information overloading also poses serious troubles. While facing massive amounts of information, users find it difficult to find the information they need. What's more, there are duplicate messages and users cannot find all required information in one site. The smart campus based on mobile internet combines personalized data mining technology to accurately and timely deliver the information to teachers and students. Information active push technology is a new approach to proactively pass on a message to users. Common information push technologies include: poll at regular intervals, message notification, long connections between client and server.

The active push platform for smart campus provides corresponding web interface to deliver campus information, grades, borrowing expiration notification and message arrival notification. 


\section{CHINESE INFORMATION PROCESSING SYSTEM}

Chinese information processing system integration shows in two aspects: application system integration facing users and accessibility tool integration.

Application integration indicates the idea of logic integration mechanism and shows the external model of system which can be put in unified data dictionary. Then, users can check system specifications with the assistance of help orders, which are system performance, method of application and notices.

Accessibility tool integration system adopts unified data mode, ATN is a powerful tool to deal with natural language, which allows output structure in any form and can change the external form of natural language into internal form while the internal language can be deemed as deep conceptual structure. The conceptual structure of natural language can be divided into event and state, which can be perfected to realize the communication among integration systems. Besides, conceptual structure can be defined as external expression and internal expression. The external expression can be adopted in the communication among systems which indicates meaning and logic demonstration of conceptual structure. Moreover, external expression can also communicate with the supporting environment of language development so as to demonstrate the meaning of debugging. Furthermore, internal expression can be adopted in tool or external system operation.

We can suppose a document as the vector of $n$ dimensional space and establish text vector space model. Besides, the vector space model can adopt the included angle $\cos \theta$ to calculate similarity:

$$
\cos \theta=\frac{\sum_{k=1}^{n} w_{i} k \times w_{2} k}{\sqrt{\left(\sum_{k=1}^{n} w_{i}^{2} k\right)\left(\sum_{k=1}^{n} w_{2}^{2} k\right)}}
$$

\section{THE REALIZATION OF SMART CAMPUS PUSH} TECHNOLOGY BASED ON BANK SWITCHING

\section{A. Client-polling}

The active push contents mainly include borrowing expiration notification, curriculum notification, student grade information push and e-mail push notification, which should not be accepted instantly and are easy to realize without heartbeat rolling. That is to say, it is enough when client asks for treatment for dormance on initiated thread, and if it is reawakened, we can go to the server to fetch information.

\section{B. ShoRt Message}

Short message platform is one of the dominant active push approaches with high cost. This approach has to collect the mobile phone information of users in advance and if there should be changes or mobile phones choose information screening, the message won't be delivered successfully.

\section{Intelligent switch strategy of push modes}

In actual operation, the platform adopts mixed push modes to properly match the above methods based on their merits and demerits. We comb and classify the formation based on its importance, receiver and timeliness to determine the most suitable push approach. The active push flow for platform shows in Fig .1. 


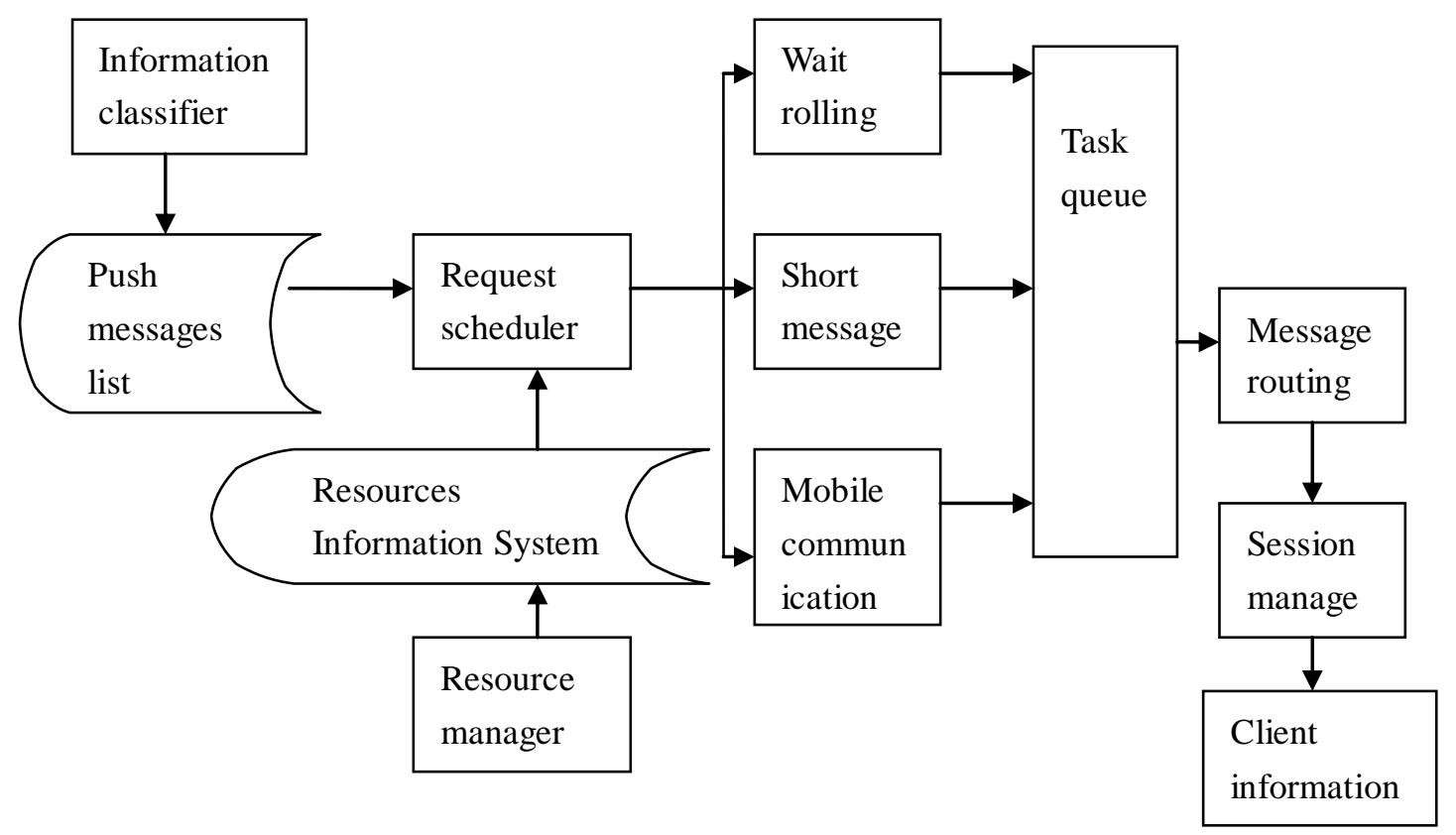

Figure 1. Design drawing for push architecture

\section{SERVER FEATURES OPTIMIZATION BASED ON INFORMATION CACHE}

The platform information includes important keys, title, main body etc and this structured information is stored in corresponding field of database and the system reads data while assembling XMPP format. However, the demerit of this approach is that it needs much time with low efficiency. We advance the push service and reduce the reading data number based on cache system and input corresponding key value in memory so as to reduce duplicated packaging. Sometimes, we cannot find XMPP information and the system shall assemble XMPP while Hibernate shall store the data in cache and deliver to client based on active push module.

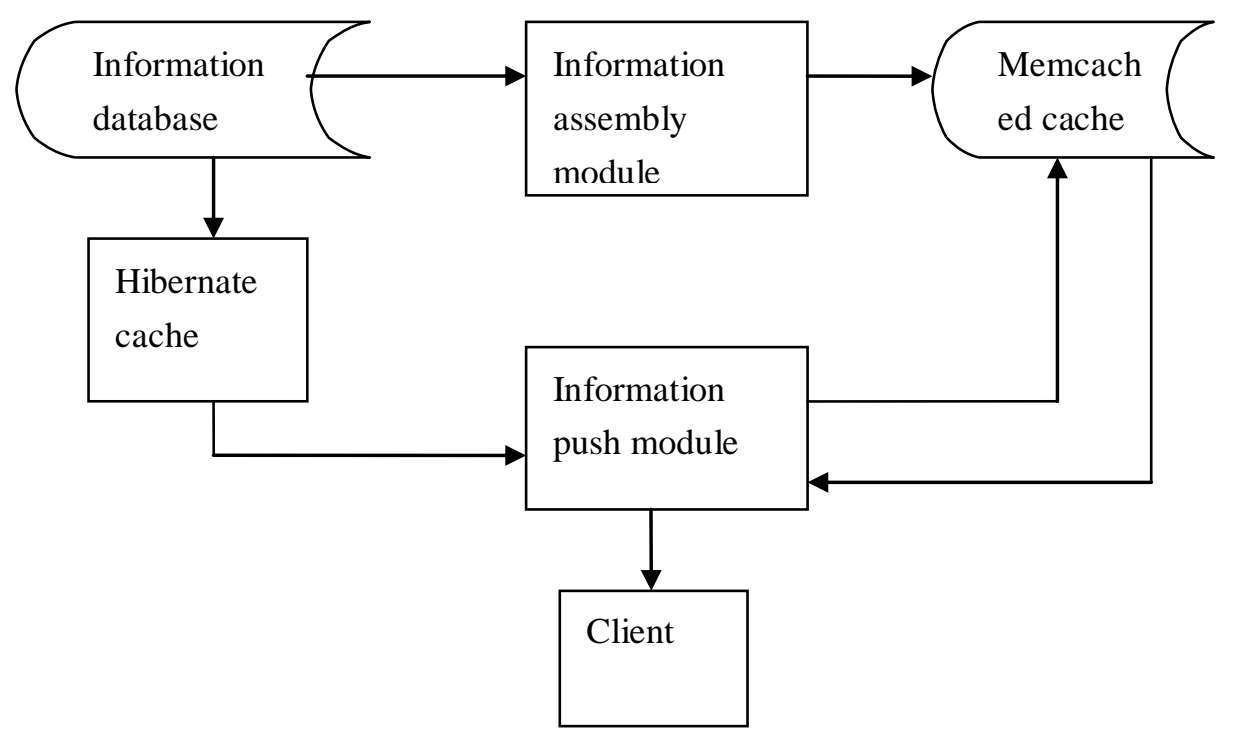

Figure 2. Schematic drawing for active push based on caching 


\section{CONCLUSION}

This paper takes mobile internet as the background, and work, life service requirement of students and teachers as starting points to mainly elaborate a smart campus service platform based on mobile internet which include diverse functions such as personalized news, active push and data analysis and can enrich and innovate the campus management model. The exploring results of this paper show as follows:

Firstly, describe the campus hot topic and find out advanced approach. Adopt ICTCLAS split system to split words and extra key words to establish knowledge representation mode for news, determine $\mathrm{k}$ initial cluster centers and find out campus hot topics by calculating word frequency of news title and K-means algorithm.

Secondly, adopt information collecting and processing technology to establish personalized news service platform with campus as topic. The platform can integrate various information via information on web crawling technique with intelligent processing so as to explore users' interests and reduce information overloading. Then, users can access to internet anytime and anywhere.

Adopt mobile communication technology to provide active push framework for non-common information. The framework provides with different push modes for different scheduling request to reduce the internet connecting time and realize optimal control on power absorption and network flow.

\section{REFERENCES}

[1] Schneider W, Shiffrin R M. Controlled and Automatic Human Information Processing: 1. Detection, Search, and Attention.[J]. Psychological Review, 1977, 84(1):N/A.

[2] Schneider, W., Shiffrin, R. M., Schneider, W., \& Shiffrin, R. M. (1977). Controlled and automatic human information processing: i. Detection Search \& Attention Psychological Review, 84.

[3] Rayner, Keith. "Eye movements in reading and information processing. Psychological Bulletin, 85, 618-660." Psychological Bulletin 85.3(1978):618--660.

[4] Laberge D, Samuels S J. Toward a theory of automatic information processing in reading $[\mathrm{J}]$. Cognitive Psychology, 1974, 6(74):293-323.

[5] Sowa J F. Conceptual Structure: Information Processing in Mind and Machine[M]// Conceptual structures : information processing in mind and machine. Addison-Wesley, 1983.

[6] Crick, Nicki R., and K. A. Dodge. "A review and reformulation of social information-processing mechanisms in children's development." Psychological Bulletin 115(1993):74-101.

[7] Dodge K A, Coie J D. Social-Information-Processing Factors in Reactive and Proactive Aggression in Children's Peer Groups[J]. Journal of Personality \& Social Psychology, 1987, 53(6): 1146-1158.

[8] Singer W. Synchronization of cortical activity and its putative role in information processing and learning.[J]. Annual Review of Physiology, 1993, 55:349-74.

[9] Bettman J R. An information processing theory of consumer choice[M]// Addison-Wesley, 1979.

[10] Salancik G R, Pfeffer J. A social information processing approach to job attitudes and task design.[J]. Administrative Science Quarterly, 1978, 23(2):224-53.

[11] Slovic P, Lichtenstein S. Comparison of Bayesian and Regression Approaches to the Study of Information Processing Judgment[J]. Organizational Behavior \& Human Performance, 1971, 6(71):649-744.

[12] Sinkula J M. Market information processing and organizational learning $[\mathrm{J}]$. Journal of Marketing A Quarterly Publication of the American Marketing Association, 1994, 58(1):págs. 35-45. 